Article

\title{
Achieving Resilience and Business Sustainability during COVID-19: The Role of Lean Supply Chain Practices and Digitalization
}

\author{
Matteo Trabucco and Pietro De Giovanni *
}

check for updates

Citation: Trabucco, M.; De Giovanni, P. Achieving Resilience and Business Sustainability during COVID-19: The Role of Lean Supply Chain Practices and Digitalization. Sustainability 2021 13, 12369. https://doi.org/10.3390/ su132212369

Academic Editor: Giovanni Leonardi

Received: 30 September 2021 Accepted: 7 November 2021 Published: 9 November 2021

Publisher's Note: MDPI stays neutral with regard to jurisdictional claims in published maps and institutional affiliations.

Copyright: (c) 2021 by the authors. Licensee MDPI, Basel, Switzerland. This article is an open access article distributed under the terms and conditions of the Creative Commons Attribution (CC BY) license (https:/ / creativecommons.org/licenses/by/ $4.0 /)$.
Department of Business and Management, Luiss University, 00197 Roma, Italy; matteo.trabucco@studenti.luiss.it

* Correspondence: pdegiovanni@luiss.it

\begin{abstract}
This paper investigates how firms can enjoy a sustainable business even during the COVID-19 pandemic. The adoption of lean coordination mechanisms over the supply chain (SC) and lean approaches in omnichannel strategies can guarantee the business sustainability and resilience. Furthermore, we investigate whether business sustainability, along with digitalization through mobile apps, Artificial Intelligence systems, and Big Data and Machine Learning enable firms' resilience. We first explore the background on the subject, identify the research gap, and develop some research hypotheses to be tested. Then, we present the data collection process and the sample, which finally consists of firms from different sectors, including retailing, electronics, pharmaceutics, and agriculture. Several logistic regression models are developed and estimated to generate findings and managerial insights. Our results show that a lean omnichannel approach is an effective practice to preserve production costs, SC visibility, inventory available over the SC, and sales. Furthermore, lean coordination with contracts can make a business sustainable by preserving quality, ROI, production costs, customer service, and inventory availability. Finally, firms can be highly sustainable through resilience when they engage in sustainable ROI, SC visibility, and sales; in contrast, the adoption of mobile apps worsens firms' resilience, which is not influenced by Artificial Intelligence and Big Data and Machine Learning.
\end{abstract}

Keywords: business sustainability; resilience; performance; omnichannel; supply chain coordination; digitalization

\section{Introduction}

The epidemic outbreak due to COVID-19 can be considered a case of Supply Chain (SC) disruption [1], which is characterized by various components: long-term disruption existence and unpredictable scaling, simultaneous disruption propagation in the SC, epidemic outbreak propagation in the population, and simultaneous disruption in supply, demand, and logistics infrastructure [2]. Unlike other disruption events, COVID-19 started small but scaled fast and dispersed rapidly over many geographic regions.

COVID-19 is an infectious disease resulting from a previous variant of the coronavirus. One of the problems that societies and countries faced during the first wave of the pandemic was the lack of equipment to successfully manage the virus. The COVID-19 outbreak has affected the global economy since January 2020, when it started to spread throughout the Wuhan area in China, and then rapidly spread throughout the globe. In September 2020, there had been cases of the disease in more than 210 countries, with 27.3 million cases of COVID-19 worldwide, 6.4 million of which occurred in the United States. Many countries around the world enforced lockdowns to slow the spread of the disease. In addition to the impacts on human health, the COVID-19 pandemic has also greatly impacted the global economy. This disruptive, unprecedented event has forced firms to rethink their business models and reshape their SCs [3]. 
The COVID-19 pandemic has caused delays and other serious problems across global SCs, highlighting how vulnerable many SCs are to unexpected disruptions [1]. In fact, being globalized in structure, SCs are highly prone to disasters like the coronavirus outbreak. This happens also because coronavirus has caused simultaneous disturbances in both supply and demand [4]. Consequently, firms should learn from this crisis and start making fundamental changes to address the pandemic to remain sustainable from a business point of view. In fact, the current disruption in the SC is affecting demand, labor, materials, and delivery to consumers, forcing firms to adapt. By analyzing the food SC in India, the authors of [5] estimated that COVID-19 has disrupted the delivery of vegetables, fruits, and edible oils, whose availability decreased by $10 \%$ on average. Fortunately, these shortages have not been followed by a price increase. By analyzing the impact of COVID-19 in France, in [6] the authors show how the pandemic impacts firms' capacity to identify and assess SC risks. This implication is due to the complexity of global disturbances that firms are not able to predict through traditional systems and that generate important negative impacts in the short-term. To overcome this limitation, the authors of [7] suggest to use advanced Artificial Intelligence systems that connect to the eco-system and mitigate the risks of disruptions in both the supply and the demand. These two disruptions have been also studied by [8], who show how the propagation of both risks has a negative influence on people and firms. They applied some propagation models to samples from Germany, Italy, and Spain and demonstrated that bottom-up approaches can induce to higher estimates than optimal solutions. These cases and applications highlight the importance of estimating the SC risks and their amplitude to properly assess the impact of disruptive events like COVID-19 on firms and the society at large.

To contribute within this research field, this research analyzes how COVID-19 affects the business sustainability by analyzing the performance as well as how firms can react to the pandemic challenges by both adopting ad hoc lean SC practices and investing in digital technology [9]. These two actions enable business sustainability by allowing firms to mitigate the negative effects of COVID-19. We start our analysis by defining the business sustainability, which considers the firms' performance and measures them as the percentage of loss that firms face due to COVID-19. When the loss is minimal, firms enjoy high business sustainability. To study sustainability in terms of performance, we focus on two main lean SC practices: lean omnichannel strategies and lean supply chain coordination mechanisms. In fact, countless firms have adopted omnichannel solutions to mitigate the negative consequences of COVID-19 adopting lean practices to better manage operations (e.g., inventory management) [10]. Furthermore, we study the impact of lean SC coordination through contracts on business sustainability. During the first wave of COVID-19, many firms faced problems related to contractual agreements with suppliers and partners [1]. SC coordination can activate mechanisms to accommodate exceptions and issues linked to COVID-19 and allow firms to maintain a high level of performance; hence, firms have used lean coordination mechanisms during this period. To pursue our research objectives, we study the role of business sustainability to achieve firm resilience. Firm resilience refers to an entity's capacity to re-establish the performance levels it had before the COVID-19 outbreak. We expect that a high level of business sustainability leads to high resilience. Finally, resilience can also be achieved through digitalization exemplified by mobile apps, Artificial Intelligence systems, and Big Data and Machine Learning. Several companies have examined these digital technologies to mitigate the negative effects of COVID-19, maintain contact with consumers, and reinvent their business models [7].

To pursue our research goals, we run a set of logistic regressions using a sample of 119 firms. We collected the data from Italy thanks to the affiliates of Confindustria that have their headquarters spread all over the world. Our goal is to produce empirical results that can be used by SCs to respond to the pandemic and guarantee pre-coronavirus performance in the short term. Specifically, this research seeks to provide items that make firms resilient and protect their performance during challenging pandemic periods like that faced during the first wave of the COVID-19 pandemic. 
The rest of this paper is organized as follows. In Section 2, we analyze the literature and derive the research hypotheses to be tested. Section 3 presents our methodology, explains the data collection, item selection, and logistic regression models. Section 4 discusses the managerial implications, and Section 5 concludes and outlines the future research agenda.

\section{Background}

It is well documented that action plans for SC disruptions vary based on the event's severity [11]. In this sense, COVID-19 represents a huge disruption and requires a wellorganized action plan [2,12]. One valid SC practice that firms can adopt during disruptive events is an omnichannel approach. The advent of COVID-19 pushed firms and people to use different channels to access to goods and services, with the result of deeply modifying their behaviors [13]. The literature has largely detailed the possible advantages and potential applications of the omnichannel option [14]. Among the possible advantages, in [15] and [16] the authors highlight how the omnichannel eliminates cross-channel barriers and enables integration, communication, and data sharing. All of these elements have been vital for firms and consumers during the COVID-19 period due to social immobility and distance, limited access to shops and retailing, and reduced stock availability. Pursuit of omnichannel connections can be an effective lever to mitigate all of these challenges by combining digital and physical worlds to provide new purchasing experiences to consumers [17]. Indeed, the omnichannel requires digital technologies to integrate offline and online channels [18] by creating efficiency at all levels and become, de facto, a lean practice. While the use of the Internet, mobile apps, and social networks have stimulated the use of omnichannel solutions, the COVID-19 outbreak has accelerated its adoption and diffusion [19].

This challenging path has allowed firms to use omnichannel options during the first wave of the COVID-19 pandemic; by doing so, firms were able to carry out their business affairs and reach consumers through different selling options in an efficient way. Therefore, the omnichannel approach resulted in a real opportunity to guarantee minor damage to firms' performance, thus becoming a lean practice. Hence, a lean omnichannel is a strategy through which firms adopt and manage omnichannel solutions aiming at efficiency and zero waste. Through this research, we will refer to this outcome as business sustainability, following the work by [20], to represent firms' capacity to be sustainable during disruptive events in terms of economic, environmental, and social performance. Furthermore, we extend this definition to also account for operational performance, which are indeed driven by supply chain objectives. This extension is new in the domain of sustainable and green SC management; therefore, it highlights the theoretical contribution offered by this study. Although firms lost a marginal slice of performance during the COVID-19 pandemic, their business model was properly organized during the pandemic period, and performance was highly sustainable. Within this framework, we seek to contribute to the literature by investigating whether the lean omnichannel option can be an effective driver to achieve business sustainability.

So far, the literature does not analyze the adoption of an omnichannel strategy to prevent performance deterioration due to shocks and challenges that arise. In fact, the literature focuses on omnichannel as a strategy to pursue several types of targets like stock reduction and availability [21], delivery time [10], customer journey and experience [22]. To our knowledge, there is only one study that deals with the use of omnichannel as an option to mitigate the risks due to COVID-19. The authors of [23] studied whether omnichannel retailers that experienced external and internal SC disruptions during the pandemic were able to handle the risks. Among the external disruptions, firms experienced consumers moving from off-line to online channels with the consequence of being not able to fully satisfy the demand. Among the internal disruptions, surely both front- and back-end operations have been the most relevant. These disruptions can be solved by 
adopting an agile approach, which can be implemented by unlocking investments and making quick actions.

We contribute in this research framework by shifting the omnichannel paradigm from traditional omnichannel to lean omnichannel. The latter will be characterized by an omnichannel strategy that can easily switch from a traditional business environment to a risky setting due to disruptive events. Accordingly, we hypothesize that:

Hypothesis 1 (H1). A lean omnichannel strategy implemented during the COVID-19 period enables business sustainability.

To pursue a comprehensive analysis of the business sustainability, we focus on several performance indicators, specifically return on investments (ROI), sales, and production costs (economic sustainability), quality, customer service, and delivery time (operational sustainability), $\mathrm{CO}_{2}$ emissions (environmental sustainability), employees' wages (social sustainability), SC visibility and inventory availability over the SC (sustainable SC).

During the COVID-19 pandemic, SC members were forced to adapt their plans and goals in response to the change in demand due to the worldwide lockdown [1]. Usually, suppliers' agreements and contractual schemes are static and rarely consider outbreak events [24]. In fact, one common assumption in the literature of contractual mechanisms in SC management is that the demand is known, suppliers have perfect information, and the operational implications can be excluded from the analysis of optimality. In reality, disruptive events that change these factors are very common; for example, the outbreak of SARS caused a huge gap in the supply of respirators and disinfectors, and the mad cow disease epidemic caused a significant shift in the demand for beef [25].

Coordination within the SC is usually achieved through contracts when suppliers consider the exogenous events happening in the ecosystem [26]. These contracts are designed to manage traditional inter-relationships between SC parties [27] as well as to consider exceptions linked to disruptive events and stochastic events. SC coordination is highly linked to the commercial agreements among SC parties to achieve a common goal. The work by [27] reveals all possible contractual agreements that firms can use in SC management. Later, the authors of [28] introduced the issue of coordination within cases of demand disruption. Hereby, coordination aims at revising a production plan after a disruption has occurred, instead of during the planning stage. The underlined reason for this type of coordination is the impossibility to predict all contingencies; consequently, providing guidance for revising a predetermined plan can be as important as making the plan itself [29].

There is a huge difference between coordination under normal settings and coordination under disruptive events; in the latter case, the shift in demand will cause several business threats and supply risks [4]. We believe that firms design their coordination mechanisms to face these new issues linked to disruptive events like the COVID-19 pandemic, making lean coordination. The latter represents the coordination aiming at reducing the contract complexity to focus on the important aspects of the business. Hence, it would lead to a simplification of procedures, agreements, and negotiation, to focus on the core business. We expect that firms that are deeply engaged in SC management have adjusted their contractual agreements to consider the negative consequences of COVID-19 and thus to achieve high levels of coordination even during these challenging periods. Accordingly, we hypothesize that:

Hypothesis 2 (H2). A lean coordination pursued during the COVID-19 period enables business sustainability.

During the COVID-19 pandemic, several discussions have been initiated in academia in relation to resilience. The concept of resilience was first introduced by [29], who wanted to represent a system's adaptability and recoverability in addition to its ability to absorb disruptions [30], which can occur within interconnected and complex systems [31]. Other 
definitions found in the literature share a common perspective on resilience, which overcomes the recovery boundary and implies a certain level of flexibility improvisation and ability to adapt to extraordinary events, both positive and negative [32,33] use Big Data to identify the structure of resilience, that is, a multifaceted construct composed of SC resilience, infrastructural resilience, community resilience, and resource resilience. All of these ingredients linked to resilience can be activated by developing trust, information sharing, quality of information, and public and private partnerships. By doing so, firms and SCs can better deal with physical catastrophes and make resilient business models.

Previous literature has developed several definitions of resilience: the authors of [34] emphasize the ability of an organization to react and recover from disturbances, with minimal effect on its dynamic stability; in [35] the authors define three properties for a system resilience, exemplified by absorptive, restorative, and adaptive capabilities. The first property represents how much a system "can automatically absorb the impacts of system perturbations and minimize consequences with little effort". The second focuses on exogenous system repair, while the third property measures endogenous mechanisms to respond to disturbances. In [36], the authors investigate the concept of reactivity, which is the capability to perform operationally and economically under unexpected conditions. Firms and supply chains need a new managerial orientation that allows firms facing unexpected events not to experience underperformance [36]. When firms' reactivity is high, their capacity to recover their financial performance after an unexpected event is also high. In the same line, the authors of [37] highlight the need for adoption of a responsive system approach to manage pandemics like COVID-19. For example, traditional resilience practices of holding inventory to proactively manage a disaster for some weeks might not be adequate. Rather, firms and SCs should adopt a flexible redundancy approach to make both systems and networks less sensitive to unexpected outbreaks.

Within the challenges imposed by COVID-19, firms and SCs have been asked to be highly resilient, that is, to demonstrate the ability to quickly adjust to a new reality [38]. When firms enjoy robust systems and performance, their resilience can be fast and effective [2]; in fact, resilience requires favorable economic conditions, resources, investments, organizational changes, and market opportunities [38]. Firms enjoying business sustainability have much higher chances for resilience, especially considering challenging periods like the COVID-19 pandemic. Accordingly, we hypothesize that:

Hypothesis 3 (H3). Business sustainability during the COVID-19 period enables firms' resilience.

In addition to the business sustainability, we seek to analyze the role of digital transformation in performance resilience. In general, digital technologies facilitate the adoption of cyber-physical integration principles in manufacturing, logistics, and SCs [39] and guarantee quick response to incoming risks linked to SC processes [10]. As highlighted by [40], digital technologies are profoundly modifying operations and SC management, thereby helping firms to predict the future and identify possible disruptive events. For example, Big Data enables several advantages, like an improved decision-making process, operational efficiency, reputational control, fraud detection, and prediction of unexpected events $[10,41,42]$.

During the COVID-19 pandemic, one of the main issues that firms faced was reaching consumers. The lockdown periods imposed all over the world created distance between consumers and firms, with the consequence that firms could not properly predict demand, collect information from consumers, or even reach locations and places. To mitigate these unfortunate situations, firms have implemented and adopted ad hoc digital technologies that facilitate a connection between firms and consumers in a digital world. This represented an amazing opportunity for firms and SCs, even though connections within the physical world were quite limited during the first wave of the COVID-19 pandemic. The existing literature demonstrates the importance of the adoption of digital technologies to manage relationships with consumers and SC members all over the world [39]. Within this 
context, our goal is to analyze how digital technologies can contribute to firms' resilience. Accordingly, we hypothesize that:

Hypothesis 4 (H4). The adoption of digital technologies during the COVID-19 period enables firms' resilience.

In this research, we focus on three digital technologies, specifically mobile apps, Artificial Intelligence, and Big Data and Machine Learning.

All research hypotheses are summarized in the conceptual model displayed in Figure 1.

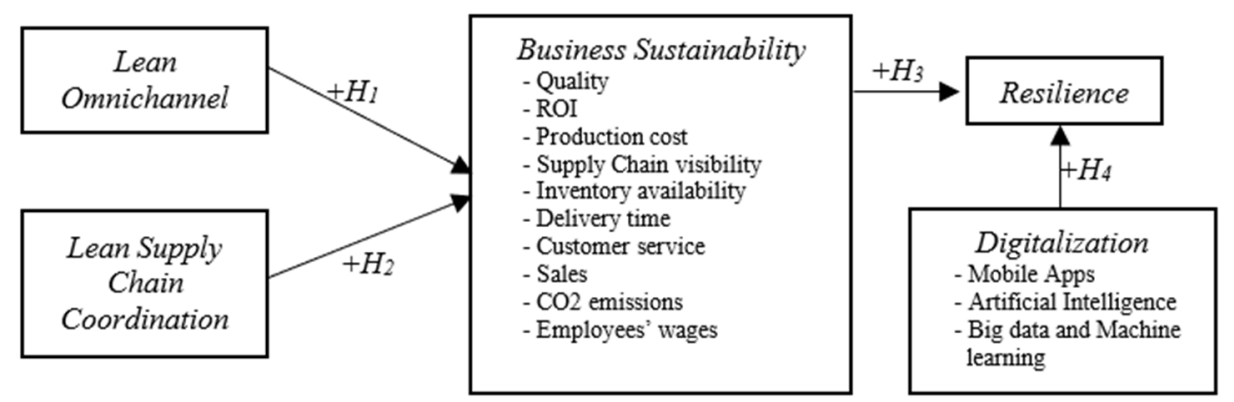

Figure 1. Conceptual model.

\section{Methodology}

\subsection{Data Collection}

The collection of data started in July 2020, when the first wave of COVID-19 was coming to an end. We asked Ph.D. students, academics, managers, and professionals to analyze the content validity of a questionnaire. After several interviews and trials, we reached a final version of the questionnaire, which was submitted to 635 firms selected among the Confindustria (Confederation of Italian Industry) affiliates.

To pursue the objectives of this study, several items are used to measure business sustainability. First of all, we focused on the following performance indicators: quality, ROI, costs, SC visibility, delivery time, customer service, inventory availability over the SC, $\mathrm{CO}_{2}$ emissions, employees' wages, and sales. Quality refers to the product quality, which indicates the perception of the degree to which the product or service meets customers expectations. ROI represents the return on investment, which evaluates the efficiency of an investment and the return relative to the investment cost. Cost is the marginal production cost. SC visibility is the ability of parts, materials, or goods to be observed, identified, and evaluated by all supply chain members, independent of their position along the chain. Delivery time refers to the period between the purchase of a product and the moment in which this product is effectively delivered to consumers. Customer service is the interaction between a firm's personnel and customers, ensures the consumers' satisfaction, and encourages future transactions. Inventory refers to the stock availability in warehouses and within the SC. Sales refers to the amount of goods sold. Relative to these performance indicators, we asked the following question: "COVID-19 induced a decrease in Performance X of _\%", with Performance X = \{ Quality, ROI, Cost, SC visibility, Delivery time, Customer service, Sales, SC Inventory, $\mathrm{CO}_{2}$ emissions, Employees' wages\}. Hence, we measure the business sustainability by computing the indicator Sustainability of Performance $X=1-$ Loss induced by COVID-19 for Performance $X$.

We measured firms' resilience in terms of time they would eventually need to recover the performance lost due to COVID-19. The firms could choose among 4 possible options: recover the performance lost within 3 months, 6 months, 12 months, or more than 12 months. To pursue the objectives of this study, we used these pieces to identify firms' resilience. Then, we asked firms whether they adopted omnichannel strategies and undertook ad hoc coordination mechanisms during the first wave of COVID-19. These items were collected through some dummy variables, having a value of " 0 " if the firm does 
not adopt it or "1" if the firm adopts one of these managerial practices. Finally, we also used a dummy variable to capture the digital technologies that firms implemented during the COVID-19 period by asking whether they adopted mobile apps, Artificial Intelligence systems, or Big Data and Machine Learning.

To homogenize the measure of business sustainability to the other variables, which are all dummy variables, we selected the boundary value of $20 \%$ to determine whether a firm was robust (losses are lower than $20 \%$ ) or fragile (losses are higher than $20 \%$ ). The threshold of $20 \%$ was selected because of the match between the literature and the policies that the governments adopted against COVID-19. Regarding the literature, the authors of $[7,10]$ demonstrated empirically that an unexpected shock is challenging for supply chains only when it has an impact on performance greater than $20 \%$. In such a case, it can justify the use of some practices to absorb these negative consequences (e.g., blockchain, Artificial Intelligence, vendor management inventory, and coordination). Furthermore, many governments applied several supporting measures for firms facing performance losses. For example, governments have set some supportive measures when the sales decreased of a certain percentage over a period compared to the year before. This percentage has been fixed by the government in some instances (e.g., in Italy, firms experiencing a downward trend in total revenues during the first wave of COVID-19 compared to the previous year could receive some aid proportional to their loss (Ministry of Economy and Finance-MEF, www.mef.gov.it/en/covid-19/decreti-ristori.html, accessed on 1 September 2021)), although it has been derived according to ad hoc procedures in some countries (e.g., in the UK, firms can compute their relief rate by using the procedure for Business rates relief: Retail discount-GOV.UK (www.gov.uk, accessed on 1 September 2021)).

\subsection{Data Description}

Among the firms that we contacted, 119 responded after 10 weeks. We used the twoproportion t-test to check for the representativeness of the sample composition. By using the variable "company type," we obtained insignificantly different proportions between the sample and the population, with $p$-value $=0.65$. All details of the sample are displayed in Table 1 and all survey questions can be found in the Appendix A.

Table 1. Sample composition.

\begin{tabular}{|c|c|c|c|c|c|c|c|c|c|c|c|}
\hline Employees & $\#$ & $\%$ & Country & $\#$ & $\%$ & Industry & $\#$ & $\%$ & Professionals & $\#$ & $\%$ \\
\hline$<50$ & 31 & $26.05 \%$ & Italy & 36 & $30.25 \%$ & Retailing & 55 & $46.22 \%$ & SC manager & 30 & $25.21 \%$ \\
\hline 50-99 & 38 & $31.93 \%$ & France & 19 & $15.97 \%$ & Electronics & 25 & $21.01 \%$ & CEO-President & 41 & $34.45 \%$ \\
\hline $100-200$ & 40 & $33.61 \%$ & UK & 10 & $8.40 \%$ & Pharmaceutics & 11 & $9.24 \%$ & $\begin{array}{l}\text { Production } \\
\text { manager }\end{array}$ & 22 & $18.49 \%$ \\
\hline \multirow[t]{5}{*}{$>200$} & 10 & $8.40 \%$ & Spain & 8 & $6.72 \%$ & Agriculture & 23 & $19.33 \%$ & $\begin{array}{l}\text { Purchasing } \\
\text { manager }\end{array}$ & 11 & $9.24 \%$ \\
\hline & & & Germany & 12 & $10.08 \%$ & Others & 5 & $4.20 \%$ & Others & 15 & $12.61 \%$ \\
\hline & & & Portugal & 8 & $6.72 \%$ & & & & & & \\
\hline & & & Belgium & 10 & $8.40 \%$ & & & & & & \\
\hline & & & Others & 16 & $13.45 \%$ & & & & & & \\
\hline
\end{tabular}

The respondent sample can be considered appropriate for this study, as it was composed of top-level executives in the positions of SC managers (25.21\%), CEO-president $(34.45 \%)$, production managers $(18.49 \%)$, purchasing managers $(9.24 \%)$, and other professionals $(12.61 \%)$. In addition, firms have different sizes in terms of number of employees, in the ranges of $<50(26.05 \%), 50-99(31.93 \%), 100-200(33.61 \%)$, and $>200$ employees $(8.4 \%)$. Responses from the various sectors were distributed as follows: electronics $(21.01 \%)$, pharmaceuticals $(9.24 \%)$, agriculture $(19.33 \%)$, retailing $(46.22 \%)$, and others $(4.2 \%)$. Firms surveyed belong to different countries, specifically Italy $(30.25 \%)$, France $(15.97 \%)$, the UK $(8.40 \%)$, Spain $(6.72 \%)$, Germany $(10.08 \%)$, Portugal $(6.72 \%)$, Belgium $(8.40 \%)$, and others $(13.45 \%)$, which includes the Netherlands, Finland, and Sweden. Several approaches 
were used to assess non-response bias. The first approach consisted of comparing early to late respondents (i.e., first and second to third surveys). A one-way ANOVA revealed no significant differences between early and late responses for any of the items. We also used size and total revenue, finding that no significant difference exists between groups.

Figure 2 displays firms' resilience in percentages, which are distributed as follows: 59 firms can recover in less than 3 months (49.58\%), 55 firms can recover in less than 6 months (46.22\%), 4 firms can recover in less than 12 months (3.36\%), and 1 firm can recover in more than 12 months $(0.84 \%)$. Accordingly, firms turn out to be most likely optimistic by the end of the first wave regarding the chance to recover quickly and restore their business affairs and volumes at the pre-COVID levels either in less than 3 months or in less than 6 months. Since the most of the firms links to these two categories, we created a dummy variable capturing resilient firms with label " 1 ", which will be able to recover in less than 3 months, representing $49.58 \%$ of the sample, and non-resilient firms with label " 0 ", which will be able to recover in more than 3 months and representing $50.42 \%$ of the sample.

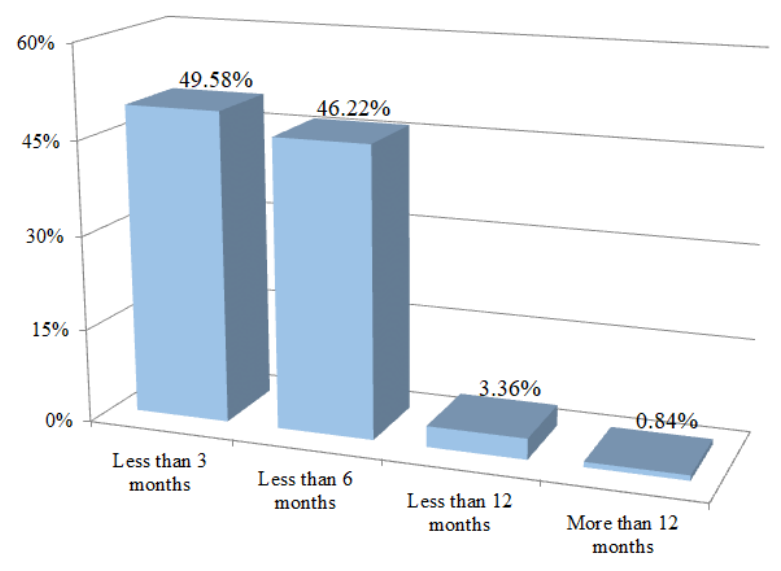

Figure 2. Distribution of firms' resilience.

\section{Results and Discussion}

To pursue the objectives of our study, we ran a set of logistic regression models in Python. For each mode, we report the following outcomes: coefficients, recall, precision, and F1 score. The coefficients indicate how the independent variables explain the dependent variable. Training accuracy represents the accuracy of a model regarding the data used to build it, while testing accuracy shows the accuracy of the model on the dataset used for testing. The split between training and testing data was 70/30, respectively. For each model, we derived the confusion matrix, which is a holistic tool for representing true and false positive and negative results. Accordingly, we derive a set of indicators: (1) Recall, which is the ratio of correctly predicted positive observations to all the observations; (2) Precision, which is the ratio of correctly predicted positive observations to the total predicted positive observations; and (3) F1 score, the weighted average of precision and recall.

\subsection{Omnichannel and Business Sustainability (Hypothesis 1)}

Our first analysis focuses on the impact of lean omnichannel strategies on business sustainability; therefore, we ran eight regression analyses corresponding to the performance indicators that we seek to analyze. The general equation that we used for Model 1 is:

$$
\text { Business Sustainability of Performance } X=\frac{e^{\alpha+\beta * \text { Lean Omnichannel }}}{1+e^{\alpha+\beta * \text { Lean Omnichannel }}}
$$

Table 2 reports the empirical results of Model 1, which then links to our first hypothesis. Our findings demonstrate that the probability to preserve the product quality during the COVID-19 pandemic does not depend on the lean omnichannel strategy 
(Coefficient $=0.4055$ with $p$-value $>0.1$ ). This inconsistence in the empirical results probably depends on the poor correlation between product quality and omnichannel strategies: usually quality is not affected by the adoption of different sales channel, since product quality is valued according to its intrinsic benefits and not by the sales channel that was previously delivered. Therefore, quality is a target that firms have always ensured, independent of the pandemic period and the adoption of lean omnichannel solutions.

Table 2. Lean omnichannel and business sustainability.

\begin{tabular}{|c|c|c|c|c|c|c|c|c|c|c|}
\hline Hypothesis 1 & Quality & ROI & $\begin{array}{l}\text { Production } \\
\text { Cost }\end{array}$ & $\begin{array}{c}\text { SC } \\
\text { Visibility }\end{array}$ & $\begin{array}{l}\text { Delivery } \\
\text { Time }\end{array}$ & $\begin{array}{l}\text { Customer } \\
\text { Service }\end{array}$ & $\begin{array}{c}\text { SC } \\
\text { Inventory }\end{array}$ & Sales & $\begin{array}{c}\mathrm{CO}_{2} \\
\text { Emissions }\end{array}$ & $\begin{array}{c}\text { Employees' } \\
\text { Wages }\end{array}$ \\
\hline Constant & 1.4663 & 1.0116 & -0.6061 & -0.2513 & 0.5878 & -0.2513 & -1.0986 & -0.7621 & -1.2202 & 1.0716 \\
\hline Coefficient & 0.4055 & -0.2697 & $1.0986^{*}$ & $1.8608^{* * *}$ & -0.7129 & 0.1178 & 1.6452 ** & $1.2730^{* *}$ & 0.2730 & 0.3052 \\
\hline $\begin{array}{l}\text { Training } \\
\text { accuracy }\end{array}$ & & & 0.6304 & 0.6956 & & & 0.6739 & 0.6521 & & \\
\hline $\begin{array}{l}\text { Testing } \\
\text { accuracy }\end{array}$ & & & 0.6190 & 0.6190 & & & 0.5238 & 0.6666 & & \\
\hline Recall & & & 0.7 & 1.0 & & & 0.5454 & 0.8571 & & \\
\hline Precision & & & 0.5833 & 0.6190 & & & 0.5454 & 0.7058 & & \\
\hline F1 Score & & & 0.6363 & 0.7647 & & & 0.5454 & 0.7741 & & \\
\hline Result & $\begin{array}{c}\text { Not } \\
\text { supported }\end{array}$ & $\begin{array}{c}\text { Not } \\
\text { supported }\end{array}$ & Supported & Supported & $\begin{array}{c}\text { Not } \\
\text { supported }\end{array}$ & $\begin{array}{c}\text { Not } \\
\text { supported }\end{array}$ & Supported & Supported & $\begin{array}{c}\text { Not } \\
\text { supported }\end{array}$ & $\begin{array}{c}\text { Not } \\
\text { supported }\end{array}$ \\
\hline
\end{tabular}

${ }^{*} p$-value $<0.10,{ }^{* *} p$-value $<0.05,{ }^{* * *} p$-value $<0.01$.

In the same vein, the results regarding the ROI demonstrate that the firms' capacity to preserve the ROI during the COVID-19 period does not depend on the lean omnichannel strategy (Coefficient $=-0.2697$ with $p$-value $>0.1$ ). This result can be explained by considering the huge disruption that this event created: COVID-19 led to decreased ROI in the long run, while the lean omnichannel strategy is a short- or medium-term strategy to allow firms to stay connected to their consumers.

In contrast, our model suggests that omnichannel application has a positive impact on the probability of keeping production costs low (Coefficient $=1.0986$ with $p$-value $=0.084$ ). This means that firms implementing lean omnichannel strategy can maintain stable costs. Since the figures for training accuracy (0.6304) and testing accuracy (0.6190) are very close, our model results are well implemented, as also confirmed by the indicators recall, precision, and F1. Therefore, this model indicates that firms adopting lean omnichannel strategies are able to maintain their cost structure during the COVID-19 pandemic. This is likely possible because firms can serve their customers through different sales channels without increasing marginal costs related to the adoption of a new way to serve the clients while lowering other costs. During the quarantine period, especially considering B2C relationships, customers have been more prone to buy through online channels instead of going directly to the stores and taking the risk of becoming infected. This means that firms not using lean omnichannel strategies must face rising costs in terms of inventory (goods must be stored for longer time periods) and delivery (more people ask for delivery respect to normal periods). Therefore, firms that implement lean omnichannel practices are more prepared to face the emergency without facing problematic cost variation. Furthermore, applying an omnichannel strategy enables firms to meet the demand, even if it changes across sales channels. By doing so, the supply chain can exploit employees' skills through re-adaptation of their functions, thereby saving personnel costs.

The results of our model suggest that a lean omnichannel strategy has a positive impact on the probability to achieve Supply Chain Visibility (Coefficient $=1.8608$ with $p$-value $=0.008$ ). This means that firms that adopt a lean omnichannel strategy can maintain and ensure visibility during the COVID-19 period. We believe that this result is based on the importance of visibility across the global supply chain. Especially for firms that outsource parts of their supply chain, the pandemic period brought a huge disruption because of the lack of components delivered from other countries. Omnichannel strategy helps these firms share data regarding the components of tracking and promoting quick response: firms within the same supply chain use visibility to be aware of a potential 
disruption and exception. In contrast, firms applying omnichannel strategy have good SC visibility through data sharing and transferring as well as shared infrastructures.

Regarding the delivery time, our results demonstrate that the probability of maintaining delivery time during the COVID-19 pandemic does not depend on a lean omnichannel strategy (Coefficient $=-0.7129$ with $p$-value $>0.1$ ). This finding depends on the severity of the disruption: even firms that are extremely integrated and use omnichannel practices cannot guarantee a delivery time in the case of global supply chain disruption, like that induced by COVID-19. For example, due to the coronavirus outbreak, government regulations prevent firms from shipping orders on time, especially because international delivery speed and availability are variable and subject to change. Additionally, several firms limit their deliveries to countries or regions that are facing lockdown as well as to other areas of the world, where international flights are less frequent and the costs for air freight transportation have increased dramatically.

Similarly to delivery time, the probability that firms can keep a high level of service to consumers does not depend on lean omnichannel (Coefficient $=0.1178$ with $p$-value $>0.1$ ). Such a result is driven by a time lapse discrepancy and by peaks in volumes: even firms that are well structured in terms of omnichannel practices face difficulty managing the demand shocks caused by COVID-19. Shifting channels from offline to online can offer a solution to improve the level of service; however, it might require an important cultural change among consumers who need time and make sacrifices to modify their purchasing and shopping habits. Similar negative implications can be induced in terms of $\mathrm{CO}_{2}$ emissions (Coefficient $=0.2730$ with $p$-value $>0.1$ ) and employees' wages (Coefficient $=0.3052$ with $p$-value $>0.1$ ), making lean omnichannel not effective in terms of environmental sustainability and social responsibility. These conditions make the omnichannel strategy less effective during COVID-19.

Regarding the supply chain inventory availability, our results show that lean omnichannel strategy increases the probability that firms can maintain control of their inventory costs during the COVID-19 outbreak (Coefficient $=1.6452$ with $p$-value $=0.017$ ). The empirical results for training accuracy (0.6739) and testing accuracy (0.5238) present a significant variation, but we can still consider its effectiveness with sufficiently good recall (0.5454), precision (0.5454), and F1 scores (0.5454). According to our results, firms adopting lean omnichannel strategies can keep their inventory availability stable also during the COVID-19 period, because omnichannel helps them optimally manage and effectively integrate stocks across all channels (e.g., brick and mortar store, online store, social media channels) and consequently keep stocks under control. In fact, a lean omnichannel approach facilitates integration across the supply chain channels, connecting for example different software into one centralized system, thereby interconnecting activities. Furthermore, omnichannel allows firms to determine easily the fastest and most cost-effective fulfillment option for each order, providing the possibility to better balance the inventory across all SC tiers.

Finally, the omnichannel strategy increases the probability that firms will restrict sales losses during the COVID-19 period (Coefficient $=1.2730$ with $p$-value $=0.041$ ); training accuracy (0.6521) and testing accuracy $(0.6666)$ are similar, validating the efficacy of the model, while recall (0.8571), precision (0.7058), and F1 score (0.7741) show significant values. Therefore, this result suggests that firms adopting lean omnichannel strategies can increase their probability of engaging in sales also during such a disruptive period. As we mentioned in the literature review, the omnichannel approach is helpful to increase sales turnover by giving people a seamless and better customer experience and increase customer loyalty. These results also apply during the coronavirus outbreak, since firms offering lean omnichannel are more sustainable in terms of sales compared to their traditional business models.

According to our results, hypothesis 1 is partially confirmed. In fact, our results confirm that lean omnichannel has a positive effect on production costs, SC visibility, SC inventory, and sales. Instead, our hypothesis is disconfirmed regarding the impact of 
lean omnichannel on quality, ROI, delivery time, customer service, $\mathrm{CO}_{2}$ emissions, and employees' wage. From these findings, we can derive the following proposition:

Proposition 1. During the COVID-19 period, firms implementing lean omnichannel strategies experienced high probability to have a sustainable business in terms of SC visibility, inventory availability, production cost, and sales. However, the presence of lean omnichannel did not guarantee high chances to have a sustainable business in terms of ROI, quality, delivery time, customer service, $\mathrm{CO}_{2}$ emissions, and employees' wages.

\subsection{Lean SC Coordination and Business Sustainability (Hypothesis 2)}

The second model that we propose seeks to explain the relationship between lean coordination and business sustainability. Additionally, in this case, we ran eight logistic regression analyses corresponding to the eight performance indicators we targeted in this research. Then, Model 2 takes the following form:

$$
\text { Business Sustainability for Performance } X=\frac{e^{\alpha+\beta * \text { Lean SC Coordination }}}{1+e^{\alpha+\beta * \text { Lean SC Coordination }}}
$$

The results of the logistic regression model are displayed in Table 3 and reveal that lean coordination is an effective practice to increase the probability to perform product quality during COVID-19 (Coefficient $=1.8659$ with $p$-value $=0.032)$. Training (0.6739) and testing accuracy $(0.6190)$ are high and similar, thus confirming model robustness. Recall (0.8), precision (0.7058), and F1 score (0.7500) also present reliable values. Therefore, our findings inform that product quality is guaranteed during the COVID-19 period through coordination by contracts. Supply chain coordination improves product quality by aligning the plans and objectives of individual enterprises and ensuring responsiveness and dynamic adjustments in the case of disruptive events like COVID-19.

Table 3. Lean SC coordination and business sustainability.

\begin{tabular}{|c|c|c|c|c|c|c|c|c|c|c|}
\hline & Quality & ROI & Costs & $\begin{array}{c}\text { SC } \\
\text { Visibility }\end{array}$ & $\begin{array}{c}\text { Delivery } \\
\text { Time }\end{array}$ & $\begin{array}{c}\text { Customer } \\
\text { Service }\end{array}$ & $\begin{array}{c}\mathrm{SC} \\
\text { Inventory }\end{array}$ & Sales & $\begin{array}{c}\mathrm{CO}_{2} \\
\text { Emissions }\end{array}$ & $\begin{array}{c}\text { Employees' } \\
\text { Wages }\end{array}$ \\
\hline Constant & -1.2528 & -0.4520 & -0.2412 & 0.1335 & 0.5390 & -0.7538 & -0.2412 & 0.9555 & -1.3966 & 1.0222 \\
\hline Coefficient & $1.8659 * *$ & $1.1992 *$ & 1.1575 * & 0.1919 & -0.0084 & $3.0051^{* * *}$ & 1.1575 * & -0.5202 & 0.3302 & 0.2929 \\
\hline $\begin{array}{c}\text { Training } \\
\text { Accuracy }\end{array}$ & 0.6739 & 0.6521 & 0.6304 & & & 0.7826 & 0.6304 & & & \\
\hline $\begin{array}{l}\text { Testing } \\
\text { Accuracy }\end{array}$ & 0.6190 & 0.8095 & 0.7142 & & & 0.6190 & 0.7142 & & & \\
\hline Recall & 0.8 & 0.8666 & 0.7333 & & & 0.5 & 0.7333 & & & \\
\hline Precision & 0.7058 & 0.8666 & 0.8461 & & & 0.875 & 0.8461 & & & \\
\hline F1 Score & 0.7500 & 0.8666 & 0.7857 & & & 0.6363 & 0.7857 & & & \\
\hline Result & Supported & Supported & Supported & $\begin{array}{c}\text { Not } \\
\text { supported }\end{array}$ & $\begin{array}{c}\text { Not } \\
\text { supported }\end{array}$ & Supported & Supported & $\begin{array}{c}\text { Not } \\
\text { supported }\end{array}$ & $\begin{array}{c}\text { Not } \\
\text { supported }\end{array}$ & $\begin{array}{c}\text { Not } \\
\text { supported }\end{array}$ \\
\hline
\end{tabular}

${ }^{*} p$-value $<0.10,{ }^{* *} p$-value $<0.05,{ }^{* * *} p$-value $<0.01$

Furthermore, our findings demonstrate that lean coordination increases firms' probability of maintaining its ROI (Coefficient $=1.1992$ with $p$-value $=0.057)$. Training accuracy (0.6521) and testing accuracy (0.8095) present a slight discrepancy, but they still give us reliable predictions, as demonstrated by the recall (0.8666), the precision $(0.8666)$, and the F1 (0.866) scores. Therefore, firms that use lean coordination mechanisms enjoy a higher chance of preserving their ROI during disruptive events like the COVID-19 pandemic. This result is in line with the extant literature about coordination: firms use coordination contracts during disruptive events to obtain a better result (e.g., [10]). This result is guaranteed also for production costs. Our empirical analysis shows that lean coordination boosts the probability of keeping the production cost at an acceptable level (Coefficient $=1.1575$ with $p$-value $=0.066)$. The training accuracy $(0.6304)$ and testing accuracy $(0.7142)$ are very close and allow us to obtain good recall (0.7333), precision (0.8461), and F1 scores (0.7857). Therefore, lean coordination can create economic sustainability in terms of production costs during the COVID-19 period. When the SC functions well, partners adjust the contractual 
terms to accommodate the disruptions imposed by the unexpected event, leading to less pressure to reduce the costs and cut resources utilization.

The positive contribution of coordination is also confirmed in terms of customer service $($ Coefficient $=3.0051$ with $p$-value $=0.0001)$. Accordingly, lean coordination increases the probability that firms will perform in terms of customer service. The training $(0.7826)$ and testing accuracy $(0.6190)$ are reliable and corroborated by good recall $(0.5)$, precision (0.875), and F1 score (0.6363). Therefore, our findings suggest that lean coordination can increase the probability to preserve the level of customer service also under disruptive events like COVID-19. Contracts can enable firms to be more aligned and inclined to offer the best possible customer service. This finding signals the strong collaborative approach that partners undertake in the SC, which is exemplified by the firms' willingness to adjust the contract terms and clauses to perform from a consumer service point of view. The benefits that lean coordination can grant are also evident when analyzing the inventory associated to the firms' business models (Coefficient $=1.1575$ with $p$-value $=0.066$ ). This means that firms coordinating the contractual terms and conditions have a high probability of maintaining their inventory management control, showing then a good robustness in terms of inventory availability. The training $(0.6304)$ and testing accuracy $(0.7142)$ are sufficiently aligned, showing good recall (0.7333), precision (0.8461), and F1 score (0.7857). Accordingly, firms that use coordination can increase their chances of keeping control of their inventory also in the case of disruptive events like COVID-19. Through lean coordination, firms can better manage the inventory over the SC, adjust the inventory stock level according to demand shocks, and still mitigate the negative consequences of the bullwhip effect.

Unfortunately, our findings reveal that lean coordination does not significantly increase firms' probability of enjoying sustainable sales developments (Coefficient $=-0.5202$ with $p$-value $=0.426$ ). Therefore, our results explain that firms can use lean coordination to reach better results internally and within the SC; instead, coordination will not increase the probability to sell more. Even in the case that the contracts are price-based, the general negative implications are that COVID-19 has been too dramatic for the general economy; firms are experiencing bankruptcies, people are losing jobs or receiving lower salaries, governments' support has become limited, etc. Therefore, more actions are needed to support firms in achieving sustainable sales. The same result is obtained relative to SC visibility and delivery time. Firms cannot rely on lean coordination to increase their chances to preserve SC visibility during the COVID-19 pandemic (Coefficient $=0.1919$ with $p$-value $>0.1$ ). This is probably linked to the nature of coordination, which refers to contractual agreements and clauses like quantity, price, rebates, and discounts. In principle, those elements do not have direct links to SC visibility, which depends on the information systems structure. Similar motivations explain the result, showing that delivery time does not depend on coordination (Coefficient $=-0.0084$ with a $p$-value $>0.1$ ). Firms that seek to maintain an operational sustainable delivery time during events like COVID-19 should look for practices that differ from lean coordination through contracts. Similar reasoning is valid for $\mathrm{CO}_{2}$ emissions (Coefficient $=0.3302$ with $p$-value $>0.1)$ and employees' wages (Coefficient $=0.2929$ with $p$-value $>0.1$, whose probability to be performed cannot be guaranteed by SC coordination because both environmental and social sustainability should be ensured independent of pandemic events.

According to our results, hypothesis 2 is partially confirmed. In fact, our results confirm that lean SC coordination has a positive effect on quality, ROI, costs, customer service, and inventory. Instead, our hypothesis is disconfirmed regarding the impact of lean SC coordination on SC visibility, delivery time, sales, $\mathrm{CO}_{2}$ emissions, and employees' wage. From these findings, we can derive the following proposition:

Proposition 2. During the COVID-19 period, firms implementing lean coordination mechanisms experienced high chances of having a sustainable business in terms of quality, ROI, costs, customer service, and inventory availability. However, lean coordination did not guarantee high chances 
to have a sustainable business in terms of SC visibility, delivery time, sales, $\mathrm{CO}_{2}$ emissions, and employees' wages.

\subsection{Business Sustainability and Resilience (Hypothesis 3)}

In this section, we present the relationships between business sustainability and resilience with the purpose of discovering which performance indicators should be preserved by firms to guarantee resilience. The latter represents the time firms would need in order to re-establish the normal business conditions if COVID-19 would currently disappear. To answer this research question, we ran a set of logistic regression models exemplified by the following equation:

$$
\text { Resilience }=\frac{e^{\alpha+\beta * B u s i n e s s ~ S u s t a i n a b i l i t y ~ f o r ~ P e r f o r m a n c e ~} X}{1+e^{\alpha+\beta * B \text { Business Sustainability for Performance } X}}
$$

The results of the regression analysis are displayed in Table 4 . Note that this table should be read differently from the results in Tables 2 and 3, since the Business Sustainability for Performance $X$ is the dependent variable in Models 1 and 2, while it is the independent variable in Model 3.

Table 4. Business sustainability and resilience.

\begin{tabular}{|c|c|c|c|c|c|c|c|c|c|c|}
\hline & Quality & ROI & Costs & $\begin{array}{c}\text { SC } \\
\text { Visibility }\end{array}$ & $\begin{array}{l}\text { Delivery } \\
\text { Time }\end{array}$ & $\begin{array}{l}\text { Customer } \\
\text { Service }\end{array}$ & $\begin{array}{c}\text { SC } \\
\text { Inventory }\end{array}$ & Sales & $\begin{array}{c}\mathrm{CO}_{2} \\
\text { Emissions }\end{array}$ & $\begin{array}{c}\text { Employees' } \\
\text { Wages }\end{array}$ \\
\hline Constant & 0.0117 & -0.5390 & 0.4855 & -0.5878 & 0.9555 & 0.3102 & 0.0800 & -0.1823 & -1.0005 & 1.0382 \\
\hline Coefficient & 0.2113 & $1.5888^{* *}$ & 0.0899 & $1.3762 * *$ & -0.6678 & 0.5371 & 0.6131 & $1.0696^{*}$ & 0.3225 & 0.2782 \\
\hline $\begin{array}{c}\text { Training } \\
\text { Accuracy }\end{array}$ & & 0.6956 & & 0.6739 & & & & 0.5217 & & \\
\hline $\begin{array}{l}\text { Testing } \\
\text { Accuracy }\end{array}$ & & 0.6666 & & 0.6190 & & & & 0.6666 & & \\
\hline Recall & & 0.9090 & & 0.7272 & & & & 1.0 & & \\
\hline Precision & & 0.625 & & 0.6153 & & & & 0.6666 & & \\
\hline F1 Score & & 0.7407 & & 0.6666 & & & & 0.8 & & \\
\hline Result & $\begin{array}{c}\text { Not } \\
\text { supported }\end{array}$ & Supported & $\begin{array}{c}\text { Not } \\
\text { supported }\end{array}$ & Supported & $\begin{array}{c}\text { Not } \\
\text { supported }\end{array}$ & $\begin{array}{c}\text { Not } \\
\text { supported }\end{array}$ & $\begin{array}{c}\text { Not } \\
\text { supported }\end{array}$ & Supported & $\begin{array}{c}\text { Not } \\
\text { supported }\end{array}$ & $\begin{array}{c}\text { Not } \\
\text { supported }\end{array}$ \\
\hline
\end{tabular}

${ }^{*} p$-value $<0.10,{ }^{* *} p$-value $<0.05$.

Our findings demonstrate that firms' ability and probability of being resilient do not depend on quality (Coefficient $=0.2113$ with a $p$-value $>0.786$ ). This result is probably linked to internal nature of quality, which is not affected by external shocks like COVID19. Therefore, our results suggest that firms aiming at resilience should not look at the operational sustainability in terms of quality to achieve their target. Similarly, firms ability to be resilient does not depend on production cost (Coefficient $=0.0899$ with a $p$-value $>0.883$ ). This result is probably linked to the fact that the cost structure changed considerably due to the coronavirus outbreak, and firms lost important economies of scales and scope due to the business stoppage. Therefore, the economic sustainability expressed in terms of cost has been quite a challenge for firms, and recovery will be very difficult.

In the same vein, our model explains that firms' probability to be resilient does not depend on loss linked to delivery time (Coefficient $=-0.6678$ with a $p$-value $>0.304$ ). This result comes with the decrease in control that firms have over the delivery time due to the global SC disruption and the related delay in the worldwide supply network. Accordingly, providing an operationally sustainable delivery time does not guarantee a higher probability to recover within the short time period. A similar result is obtained when analyzing the sustainability of customer service (Coefficient $=0.5371$ with a $p$-value $>0.393$ ) and inventory availability (Coefficient $=0.6131$ with a $p$-value $>0.1$ ). Although firms have invested during the COVID-19 period in providing a high level of customer service and thus preserve its robustness, the probability of being resilient does not increase. This outcome can be linked to the strong relationship that exists between consumers and firms, which has been created over time and is not perturbed by COVID-19. Therefore, increasing the level of service for customers will not translate into a higher probability of quickly recovering the business affairs, since this will probably already be the case. That is, when the pandemic 
period is over, both firms and consumers will go back to normality and reactivate their standard relationships, independent of the operational sustainability achieved in terms of level of service. The same applies for inventory management. That is, firms can manage inventory internally and over the SC will not be able to recover their business affairs faster because the management of stocks is always optimized, independent of the existence of COVID-19. Similarly, neither the environmental (Coefficient $=0.3225$ with $p$-value $>0.1$ ) or the social sustainability (Coefficient $=0.2782$ with $p$-value $>0.1$ ) that we study turn out to be positively impactful for resilience, showing a certain distance between environmental performance and social outcomes with operational aspects like resilience.

In contrast, the probability of being more resilient is linked to the sales (Coefficient $=1.0696$ with $p$-value $=0.085$ ); therefore, firms preserving $80 \%$ of sales during COVID-19 will be able to restore their business at the pre-coronavirus levels within 3 months after the end of the pandemic. The training $(0.5217)$ and testing accuracy $(0.6666)$ are similar to the good recall (1.0), precision (0.6666), and F1 scores (0.8). Sales robustness is a signal of business continuity, even during the pandemic period, which informs on the important efforts made by firms to continue selling also during disruptive moments. As previously mentioned, the adoption of an omnichannel strategy allows firms to achieve this goal.

Furthermore, our findings demonstrate that sustainability ROI has a positive impact on resilience $($ Coefficient $=1.5888$ with $p$-value $=0.014)$. This means that firms that have lost less than $20 \%$ of their original ROI due to the disruptions from COVID-19 can recover their standard business affairs within 3 months after the end of the pandemic period. The training (0.6956) and testing accuracy (0.6666) are similar, thus confirming the efficacy of the model with good recall (0.9090), precision (0.625), and F1 score (0.7407). Therefore, we can conclude that firms with a sustainable ROI will be resilient and will recover in less than 3 months.

Regarding SC visibility, the empirical results suggest that resilience is a feasible target (Coefficient $=1.3762$ with $p$-value $=0.042)$. Accordingly, firms enjoying a sustainable SC toward SC visibility can recover their business affairs at the pre-coronavirus level within 3 months after the end of the pandemic period. The training accuracy (0.6739) and testing accuracy $(0.6190)$ are similar, confirming the efficacy of the model with satisfactory recall (0.7272), precision (0.6153), and F1 scores (0.6666). Therefore, we can state that a sustainable SC visibility increases firms' probability of being resilient. Specifically, firms that maintain more than $80 \%$ of their SC visibility have greater chances to recover within 3 months.

According to our results, hypothesis 3 is partially confirmed. In fact, our results confirm that Resilience depends on sustainability of ROI, SC visibility, and sales. Instead, our hypothesis is disconfirmed regarding all other business performance. According to these results, we can derive the following proposition:

Proposition 3. During the COVID-19 period, business sustainability in terms of ROI, sales, and $S C$ visibility increases the firms' probability to be resilient, which cannot be instead improved by preserving the costs, delivery time, customer service, inventory availability, $\mathrm{CO}_{2}$ emissions, and employees' wages.

\subsection{Digitalization and Resilience (Hypothesis 4)}

In the final analysis, we analyze the links between the adoption of digital technologies and the firms' probability of being resilient. To pursue our research objective, we ran the following regression model:

$$
\text { Resilience }=\frac{e^{\alpha+\beta * \text { Digitalization }}}{1+e^{\alpha+\beta * \text { Digitalization }}}
$$

where Digitalization = Mobile Apps, Artificial Intelligence, Big Data, and Machine Learning.

Table 5 summarizes the results of our logistic regression model, which show that neither Artificial Intelligence systems nor Big Data and Machine Learning are suitable 
digital technologies to increase the firms' probability to recover in less than 3 months after COVID-19.

Table 5. Digitalization and resilience.

\begin{tabular}{cccc}
\hline & Mobile Apps & Artificial Intelligence & Big Data and Machine Learning \\
\hline Constant & 0.342 & -0.2280 & 0.3532 \\
Coefficient & $-1.2040 *$ & 0.0583 & 0.0654 \\
Training Accuracy & 0.6956 & & \\
Testing Accuracy & 0.5809 & & \\
Recall & 0.59 & & Not supported \\
Precision & 0.5846 & Not supported & \\
F1 Score & 0.61 & $* p$-value $<0.10$.
\end{tabular}

In contrast, the adoption of mobile apps influences firms' probability of being resilient, but through a different sign with regard for our expectations (Coefficient $=-1.2040$ with $p$-value $=0.062)$. Training $(0.6521)$ and testing accuracy $(0.5809)$ as well as the related recall (0.59), precision (0.5846), and F1 score (0.61) show good values. These empirical results can be linked to behavioral motivations: the adoption of mobile apps to engage consumers during COVID-19 changes purchasing and shopping habits. The length of the pandemic period led consumers to adjust their behavior and adapt to new restrictions within the shopping experience. For example, people were forced to move from physical shopping at a supermarket to the use of mobile apps for home delivery, and some will not return to their original habits. Therefore, the adoption of mobile apps to stay in contact and engage consumers during the COVID-19 period increases the probability that firms will recover their standard business affairs in more than 3 months, since they need to re-equilibrate the business model with new consumers' purchasing and shopping habits.

According to our results, hypothesis 4 is partially confirmed. In fact, our results confirm that Resilience depends on digital apps. Instead, our hypothesis is disconfirmed regarding Artificial Intelligence and Big Data and Machine Learning. From these results, we can derive the following proposition:

Proposition 4. During the COVID-19 period, firms adopting mobile apps decrease their probability for resilience. In contrast, implementing Artificial Intelligence systems, Big Data, and Machine Learning do not impact firms' probability of being resilient.

\section{Conclusions and Future Extensions}

Our research provides an analysis of practices and actions that firms can undertake to preserve their performance during the COVID-19 period and achieve business sustainability goals. The literature shows a gap in this sense because previous research did not address the following questions: can lean supply chain coordination and lean omnichannel improve the business sustainability during COVID-19? Can business sustainability and digital technology make firms more resilient during COVID-19? To answer to these questions, we developed and tested several research hypotheses by using a dataset of 119 firms and running a set of logistic regression models. Our investigation focused on firms' business sustainability, which represents firms' capacity to limit performance loss during the first wave of COVID-19. In this study, a performance indicator was considered sustainable when it decreased less than 20\% during the COVID-19 pandemic. This measure was selected according to the governments' policies that supported all firms that lost a considerable amount of business due to COVID-19. For example, firms in the restaurant industry received special aid when their sales decreased more than $20 \%$ during the COVID-19 period in Italy and in France. Accordingly, we detected sustainability in terms of performance relative to quality, service level, inventory availability over the SC, production cost, delivery time, ROI, SC visibility, and sales. We investigated whether firms 
that modified their SC operations were able to guarantee performance sustainability. We focused on two lean supply chain practices, namely lean omnichannel and lean supply chain coordination. That is, we investigated whether firms adopting lean omnichannel strategies and firms adjusting their contractual terms with SC partners to incorporate the challenges imposed by COVID-19 were able to ensure a sustainable business.

Furthermore, we focused our attention on firms' resilience. Specifically, we investigated how firms perceive the capacity to re-establish pre-COVID business affairs and focus on the time firms would need to recover their business affairs if COVID-19 had ended the day after the interview. We observed that $49.58 \%$ of the sampled firms could recover in less than 3 months (high resilience) and $50.42 \%$ of them could recover in more than 3 months (low resilience). We then investigated whether business sustainability influences firms ${ }^{\prime}$ probability for resilience. Finally, we analyzed the impact of digitalization on resilience by focusing on the adoption of digital technologies. The latter allowed firms to stay in touch, communicate, and exchange information with consumers who were unable to freely circulate the eco-system.

Our findings demonstrate that firms should invest in lean omnichannel strategies to increase their probability for business sustainability in terms of production costs, SC visibility, inventory, and sales. Therefore, managers who want to preserve one of these performance indicators during catastrophic periods like COVID-19 should invest in lean omnichannel strategies. Unfortunately, this approach is not effective for preserving ROI, product quality, delivery time, and customer service; therefore, firms should look at other SC practices to guarantee business sustainability for these performance indicators. Additionally, firms can rely on lean SC coordination to ensure business sustainability. Coordination, in fact, links to firms' contractual agreements and clauses, which can be modified during crises like COVID-19 to face all challenges with the supply chain partners. Our findings show that lean coordination increases the probability for business sustainability in terms of product quality, ROI, production costs, customer service, and inventory. Therefore, decision-makers who want to preserve one or more of these performance indicators can push for SC coordination. In contrast, coordination is not effective in preserving SC visibility, delivery time, $\mathrm{CO}_{2}$ emissions, employees' wages, and sales, which require alternative practices and solutions. We discovered that business sustainability is linked to firms' probability of resilience. Our findings suggest that sustainability for ROI, SC visibility, and sales should be pursued during challenging periods like the COVID-19 pandemic to ensure resilience. Interestingly, the latter is negatively affected by the digital transformation carried out through mobile apps, since this digital technology changes consumers' habits and way of shopping, thereby inducing consumers to adopt new and different purchasing behaviors that could be maintained by consumers even after the COVID-19 period and could require more time to re-establish firms' business affairs. In other words, Artificial Intelligence systems and Big Data and Machine Learning do not impact firms' probability for resilience.

This research has several limitations that are listed hereby to inspire future research in the same field and following the same lines. This study works with data collected at the national level. Other types of data can be collected to make the analysis more specific. We focused on two major SC practices, lean omnichannel and lean coordination, since these were easy for firms to adopt during the COVID-19 pandemic. In the future, other lean practices could be investigated like supply chain integration, network restructuring, and complexity management. We focused on seven performance indicators; therefore, future research can extend our analysis by considering other types of performance like flexibility, inventory turnover, inventory cost, and time-to-market. A follow-up study could be conducted to analyze the same research hypotheses during the second and the third waves. Finally, other digital technologies could be explored like Blockchain, Digital Supply Chain, 3D printing, Cloud computing, and Robotics. One should consider that some interesting technologies like Artificial Intelligence as well as Big Data and Machine Learning resulted to be not statistically significant. Although this is true, more research is 
needed to investigate the roles of these technologies in other contexts, like sustainability and ethics. This is a research avenue that the authors are currently exploring.

Author Contributions: M.T. and P.D.G. have equally contributed to each section of this manuscript. All authors have read and agreed to the published version of the manuscript.

Funding: This research received no external funding.

Institutional Review Board Statement: Ethical review and approval were waived for this study since the data collected were based on interviews to firms, whose answered remain anonymous.

Informed Consent Statement: Not applicable.

Data Availability Statement: Not applicable.

Conflicts of Interest: The authors declare no conflict of interest.

\section{Appendix A. Questionnaire}

Appendix A.1. General Information

1. Indicate your company type

- Manufacturer

- Wholesaler

- Distributor

- Supplier

- Retailer

- Others

2. Indicate the average number of employees in the last two years:

$-\quad<50$

- 50-99

- $100-200$

$-\quad>200$

3. Indicate your average turnover (millions) in the last two years

4. Indicate the country in which your company has its headquarter

5. Indicate your corporate role (e.g., manager, managing director, $\mathrm{CEO}$, etc.)

6. Indicate the sector in which your company works

\section{Appendix A.2. Business Sustainability}

During the period January-June 2020, in which percentage did your company experience a deterioration of performance due to COVID-19?

- Inventory availability

- Customer service

- ROI

- Sales

- Quality of products

- $\quad$ On-time delivery

- $\quad$ Production cost

- Supply Chain Visibility

- $\mathrm{CO}_{2}$ emissions

- Employees' wages

Appendix A.3. Supply Chain Practices and Technologies

During the period January-June 2020, which actions have been adopted to properly respond to challenges due to COVID-19?

- We adjusted the contract terms and clauses according to the pandemic situation (Supply Chain Coordination) 
- We implemented omnichannel strategies (Omnichannel)

- We adopted the following digital technologies:

- Mobile Apps

- Artificial Intelligence

- Big Data and Machine Learning

How many months would you need to restore your company's business affairs and volumes lost due to COVID-19 during the period January-June 2020?

- $\quad$ Less than 3 months

- $\quad$ Less than 6 months

- Less than 12 months

- $\quad$ More than 12 months

\section{References}

1. Choi, T.Y.; Rogers, D.; Vakil, B. Coronavirus is a wake-up call for supply chain management. Harv. Bus. Rev. 2020, 27, 364-398.

2. Ivanov, D. "A blessing in disguise" or "as if it wasn't hard enough already": Reciprocal and aggravate vulnerabilities in the supply chain. Int. J. Prod. Res. 2020, 58, 3252-3262. [CrossRef]

3. Elflein, J. Coronavirus (COVID-19) Disease Pandemic-Statistics \& Facts; Statista: Hamburg, Germany, 2020.

4. De Giovanni, P. Blockchain and Smart contracts in Supply Chain Management. Int. J. Prod. Econ. 2020, 228, 107855. [CrossRef]

5. Mahajan, K.; Tomar, S. COVID-19 and Supply Chain Disruption: Evidence from Food Markets in India. Am. J. Agric. Econ. 2021, 103, 35-52. [CrossRef] [PubMed]

6. El Baz, J.; Ruel, S. Can supply chain risk management practices mitigate the disruption impacts on supply chains' resilience and robustness? Evidence from an empirical survey in a COVID-19 outbreak era. Int. J. Prod. Econ. 2021, 233, 107972. [CrossRef]

7. De Giovanni, P. Smart Supply Chain with Dynamic VMI, Coordination and Environmental Performance. Eur. J. Oper. Res. 2021, 292, 515-531. [CrossRef]

8. Pichler, A.; Farmer, J.D. Simultaneous supply and demand constraints in input-output networks: The case of Covid-19 in Germany, Italy, and Spain. Econ. Syst. Res. 2021, 33, 1-21. [CrossRef]

9. De Giovanni, P. Digital supply chain through dynamic inventory and smart contracts. Mathematics 2019, 7, 1235. [CrossRef]

10. De Giovanni, P. Dynamic Quality Models and Games in Digital Supply Chains: How Digital Transformation Impacts Supply Chain Quality Management; Springer Nature: Berlin/Heidelberg, Germany, 2021. [CrossRef]

11. Pavlov, A.; Ivanov, D.; Werner, F.; Dolgui, A.; Sokolov, B. Integrated detection of disruption scenarios, the ripple effect dispersal and recovery paths in supply chains. Ann. Oper. Res. 2019, 7, 1-23. [CrossRef]

12. Ivanov, D.; Dolgui, A. A digital supply chain twin for managing the disruption risks and resilience in the era of Industry 4.0. Prod. Plan. Control 2020, in press. [CrossRef]

13. Simon, H.A. Administrative Behavior. A Study of Decision-Making Processes in Administrative Organizations; The Free Press: Camden, NJ, USA, 2013.

14. Grewal, D.; Levy, M. Retailing research: Past, present, and future. J. Retail. 2007, 83, 447-464. [CrossRef]

15. Brynjolfsson, E.; Hu, Y.J.; Rahman, M.S. Competing in the Age of Omnichannel Retailing; MIT: Cambridge, MA, USA, 2013; pp. 1-7.

16. Hübner, A.; Wollenburg, J; Holzapfel, A. Retail logistics in the transition from multi-channel to omni-channel. Int. J. Phys. Distrib. Logist. Manag. 2016, 46, 562-583. [CrossRef]

17. Bell, D.R.; Gallino, S.; Moreno, A. How to win in an omnichannel world. MIT Sloan Manag. Rev. 2014, 56, 45-54.

18. Akturk, M.S.; Ketzenberg, M.; Heim, G.R. Assessing impacts of introducing ship-to-store service on sales and returns in omnichannel retailing: A data analytics study. J. Oper. Manag. 2018, 61, 15-45. [CrossRef]

19. Sarmah, A.; De Giovanni, D.; De Giovanni, P. Compulsory licenses in the pharmaceutical industry: Pricing and R\&D strategies. Eur. J. Oper. Res. 2020, 282, 1053-1069.

20. Durst, S.; Zieba, M. Knowledge risks inherent in business sustainability. J. Clean. Prod. 2020, 251, 119670. [CrossRef]

21. Derhami, S.; Montreuil, B.; Bau, G. Assessing product availability in omnichannel retail networks in the presence of on-demand inventory transshipment and product substitution. Omega 2021, 102, 102315. [CrossRef]

22. Tueanrat, Y.; Papagiannidis, S.; Alamanos, E. A conceptual framework of the antecedents of customer journey satisfaction in omnichannel retailing. J. Retail. Consum. Serv. 2021, 61, 102550. [CrossRef]

23. Weber, A.N. Responding to supply chain disruptions caused by the COVID-19 pandemic: A Black Swan event for omnichannel retailers. J. Transp. Supply Chain Manag. 2021, 15, 16. [CrossRef]

24. De Giovanni, P.; Zaccour, G. A selective survey of game-theoretic models of closed-loop supply chains. 4OR 2019, 17, 1-44. [CrossRef]

25. Xiao, T.; Qi, X. Price competition, cost and demand disruptions and coordination of a supply chain with one manufacturer and two competing retailers. Omega 2008, 36, 741-753. [CrossRef]

26. De Giovanni, P. Coordination in a distribution channel with decisions on the nature of incentives and share-dependency on pricing. J. Oper. Res. Soc. 2016, 67, 1034-1049. [CrossRef] 
27. Preeker, T.; De Giovanni, P. Coordinating innovation projects with high tech suppliers through contracts. Res. Policy 2018, 47, 1161-1172. [CrossRef]

28. Qi, X.; Bard, J.F.; Yu, G. Supply chain coordination with demand disruptions. Omega 2004, 32, 301-312. [CrossRef]

29. Holling, C.S. Resilience and stability of ecological systems. Annu. Rev. Ecol. Syst. 1973, 4, 1-23. [CrossRef]

30. Tran, T.H.; Balchanos, M.; Domercant, J.C.; Mavris, D.N. A framework for the quantitative assessment of performance-based system resilience. Reliab. Eng. Syst. Saf. 2017, 158, 73-84. [CrossRef]

31. Gunasekaran, A.; Nachiappan, S.; Shams, R. Supply Chain Resilience: Role of Complexities and Strategies. Int. J. Prod. Res. 2015, 53, 6809-6819. [CrossRef]

32. Ponomarov, S.Y.; Holcomb, M. Understanding the concept of supply chain resilience. Int. J. Logist. Manag. 2009, 20, 124-143. [CrossRef]

33. Papadopoulos, T.; Gunasekaran, A.; Dubey, R.; Altay, N.; Childe, S.J.; Wamba, S.F. The Role of Big Data in Explaining Disaster Resilience in Supply Chains for Sustainability. J. Clean. Prod. 2017, 142, 1108-1118. [CrossRef]

34. Hollnagel, E.; Woods, D.D.; Leveson, N. Resilience Engineering: Concepts and Precepts; Ashgate: Aldershot, UK, 2006.

35. Vugrin, E.D.; Warren, D.E.; Ehlen, M.A.; Camphouse, R.C. A framework for assessing the resilience of infrastructure and economic systems. In Sustainable and Resilient Critical Infrastructure Systems; Springer: Berlin/Heidelberg, Germany, 2010; pp. 77-116.

36. De Giovanni, P.; Cariola, A.; Passarelli, M. Recent developments on Reactivity: Theoretical conceptualization and empirical verification. Eur. J. Oper. Res. 2013, 231, 690-701. [CrossRef]

37. Ivanov, D.; Das, A. Coronavirus (COVID-19/SARS-CoV-2) and supply chain resilience: A research note. Int. J. Integr. Supply Manag. 2020, 13, 90-102. [CrossRef]

38. Golan, M.S.; Jernegan, L.H.; Linkov, I. Trends and applications of resilience analytics in supply chain modeling: Systematic literature review in the context of the COVID-19 pandemic. Environ. Syst. Decis. 2020, 4, 222-243. [CrossRef]

39. Chiarini, A.; Belvedere, V.; Grando, A. Industry 4.0 strategies and technological developments. An exploratory research from Italian manufacturing companies. Prod. Plan. Control 2020, 31, 1385-1398. [CrossRef]

40. Wamba, S.F.; Ngai, E.W.T.; Riggins, F.; Akter, S. Transforming Operations and Production Management Using Big Data and Business Analytics: Future Research Directions. Int. J. Oper. Prod. Manag. 2017, 37, 2-9.

41. Wamba, S.F.; Akter, S.; Edwards, A.; Chopin, G.; Gnanzou, D. How 'Big Data' Can Make Big Impact: Findings from a Systematic Review and a Longitudinal Case Study. Int. J. Prod. Econ. 2015, 165, 234-246. [CrossRef]

42. Tang, C.S. Perspectives in supply chain risk management. Int. J. Prod. Econ. 2006, 103, 451-488. [CrossRef] 